\title{
A study on the prevalence of risk factors for diabetes and hypertension among school children in Majmaah, Kingdom of Saudi Arabia
}

\author{
Syed Meraj Ahmed, ${ }^{1}$ Mohammed Al Mansour ${ }^{2}$ \\ ${ }^{1}$ Department of Community Medicine and ${ }^{2}$ Department of Family Medicine, College of Medicine, \\ Majmaah University, Majmaah, Saudi Arabia
}

Significance for public health

The whole body of work done on risk factors associated with diabetes and hypertension provides a grim outlook for the burden of disease that developed and developing countries are both going to face. Health education about the presence of such risk factors and its consequences to the general population is getting drowned out in the rapid globalization of the lifestyle, diet and societal addictions in terms of technology and entertainment. A need was felt to improve the coverage of high risk populations who are at the cusp of development and to whom any positive primary prevention would matter the most since they are the precursors of our vision of a healthy future. This study would be one of the tools to encourage further exploratory studies on minimizing risk factors at an early age in a high-risk country like Saudi Arabia.

\footnotetext{
Abstract

Background. The prevalence of risk factors for diabetes and hypertension in Saudi school children has achieved epidemic proportions because of enriched lifestyles. The aim of this study is to conduct a baseline study of such risk factors in a young population at the cusp of high-end technology and material comfort.

Materials and Methods. A cross-sectional study was done among school children using parental assisted self-questionnaires and anthropometric assessment of their vital statistics. This study, including planning, data collection and analysis, and the writing of the first draft, was conducted from March 2015 to October 2016 after ethical approval was obtained. Cluster sampling was done for the schools, and stratified randomized sampling was performed to choose a total of 794 male and female school children. SPSS software was used for data analysis.

Results. It was found that $11.6 \%$ of the children had a body mass index (BMI) above the normal range. The waist-to-height ratio was elevated in $16.8 \%$ of the children. Other risk factors of note were a high prevalence of sedentary habits $(43 \%)$, daily consumption of carbonated sugary drinks $(36.4 \%)$, and eating at fast food restaurants most days of the week (17\%).

Conclusions. This gradual buildup of risk factors for diabetes and hypertension at an early age is a morbid indicator of an epidemic whose outcome has been determined. Most of these modifiable risk factors are amenable to change through concentrated efforts to educate, train and inculcate healthy habits among children and their families.
}

\section{Introduction}

Risk factors for diabetes and hypertension have been ever increasing among children in most parts of the world, with many articles clearly warning about ominous outcomes, which are often overlooked by pediatric physicians. ${ }^{1}$ The effect of the digital revolution in present times is such that even children are suffering detrimental health effects from sedentary lifestyles. ${ }^{2}$ Studies have shown that, subsequently, the prevalence of cardio-metabolic risk factors has increased in childhood populations within the past decade. ${ }^{3,4}$ A significant association has been shown in several studies of diabetes and pre-existing obesity done worldwide, with recommendations to reduce the prevalence of these risk factors at an earlier age to decrease the incidence of cardio-metabolic disorders. ${ }^{5}$ This correlates with findings among Asian children who were reported to be at increasingly higher risk of developing NIDDM, hypertension, dyslipidemia, and coronary heart disease $^{6,7}$ as a result of obesity.

A highly probable scenario for a bleak future would be a significant spurt in cardio-metabolic disorders and their complications, many of which are readily preventable. ${ }^{8}$ We are still in that stage where though the scientific community fully recognizes the untoward consequences, the general population still needs to be made aware of the risks of diabetes, hypertension, and other cardiovascular disorders, and the preventative strategies that can be used to avoid them.

Prevalence studies on diabetes and hypertension among adults in Saudi Arabia are well documented. ${ }^{10,11}$ Mapping the risk factors present in school children and adolescents would be of great significance since studies have shown that they are a population that can be molded to lead a healthier life. ${ }^{12,13}$ Furthermore, this population is more prone to gravitate towards junk food and a sedentary lifestyle because of the overwhelming presence of social media and other digital age products. ${ }^{14}$ Studies that have focused on children in Saudi Arabia are few and far between with no uniform representation from around the country. ${ }^{15-17}$ The present effort was made to identify risk factors associated with diabetes mellitus and hypertension, targeting school children in Majmaah, Saudi Arabia and subsequently make suggestions to obviate these prospective health disorders through non-medical means.

\section{Materials and Methods}

This study was conducted in the city of Majmaah in Riyadh Province, Saudi Arabia. Majmaah is populated with a mix of ethnic Saudi people and expatriates. This was a descriptive, crosssectional and institutional based study among primary school children aged 7 to 14 years. There are 263 government schools in 
Majmaah; 123 schools are for boys and the remaining 140 are for girls. A total number of 13,137 students attend these primary schools, including 6,686 males and 6,451 female students. All the above data was provided by the Ministry of Higher Education, Majmaah University, Majmaah, Saudi Arabia. The study was initiated on $1^{\text {st }}$ March 2015 and ended on $30^{\text {th }}$ October 2016.

Review of previous lifestyle studies indicated the approximate prevalence of risk factors for diabetes and hypertension among the school children was $20 \% .{ }^{18,19}$ A total sample size of 950 (rounded off from 983) students was calculated using the formula $n=\left\{Z^{2} p\right.$ $(1-\mathrm{p})\} / \mathrm{d}^{2}(\mathrm{z}=1.96, \mathrm{P}=0.20,1-\mathrm{P}=0.80, \mathrm{~d}=0.05$, design effect=4). The study population was further determined by choosing 12 male and female schools each through cluster sampling. The 12 schools were chosen taking into consideration the duration of data collection required before the beginning of the examinations in the schools and the availability of the school children. Participants were chosen from each of the 12 schools by proportionately stratified random sampling to maintain homogeneity of representation. Thus, a total of 475 male and 475 female school children were chosen for the study. Children were advised to wear loose light clothing and assemble before school or during break as per their convenience for anthropometric and blood pressure measurements. Their shoes, any accessories and outer layers of clothing were removed, after which standing height was measured to the nearest $0.1 \mathrm{~cm}$ and body weight obtained to the nearest $0.1 \mathrm{~kg}$ on calibrated digital scales. Scales were recalibrated after each use. Female investigators were trained to gather data from female children since mixing of males and females is not allowed in Saudi culture.

Parents or guardians filled in a semi-structured, close-ended questionnaire at home. A two-step evaluation of the questionnaire was used to validate it. First, the questionnaire was given to public health and epidemiology experts in the College of Medicine at Majmaah University to ensure that the questions were consistent with the objectives of the study and that no confusing, leading or inappropriate questions were included, that would need to be modified or removed. Secondly, a pilot study was done on 60 participants (the parents/guardians of the school children) picked randomly from one of the schools. This was done to determine whether the respondents would pay attention to the questionnaire content, and provide responses to all the items. The questionnaires were again scrutinized and assessed for their validity based on these pilot study responses before initiating the actual survey. Finally, a form in Arabic and English with a brief explanation about the objectives of the study, was attached to the questionnaire, to seek informed consent from the parents/guardians. Risk factors used in the study were based on both physical measurements and presence of dietary and lifestyle habits. ${ }^{19}$

The child was considered to have a first-degree family history if the respondent indicated that the natural mother, the natural father, or any full sister or brother had diabetes or hypertension. Body mass index (BMI) was calculated as body weight in $\mathrm{kg} /$ height in meters. ${ }^{2}$ We applied cut off points as given in the WHO guidelines ${ }^{20}$ for participants with ages ranging from 6 to 14 years for the assessment of overweight and obesity. Those $\geq 85^{\text {th }}$ percentile were considered overweight, and $\geq 95^{\text {th }}$ percentile were obese, while those $<85^{\text {th }}$ percentile were considered to be of desirable weight or lean. A qualified physician measured the waist circumference (exerting the same standard pressure on the tape) at the midpoint of the lowest rib cage and the iliac crest, to the nearest 0.1 $\mathrm{cm},{ }^{21}$ in a standing position during end-tidal expiration. If a student was absent or refused to participate in the study, the next student in the register was taken with his or her consent. A total of 794 students completed the study. Since there are quite rigid cultural and religious values followed by the citizens of Saudi Arabia, the num- ber of female participants was less than male participants.

Informed written and signed consent was obtained from the parent/guardians of all participants included in the study.

All the data was entered in SPSS version 22 software and analyzed for statistically significant outcomes. Chi-square tests and percentiles were used for gathering the findings of the results.

\section{Results}

This study was done to assess the prevalence of risk factors like body mass index (BMI), weight-to-height ratio (WHR), positive family history for diabetes and hypertension, food and drink intake habits and sedentary lifestyle among male and female primary school children in Majmaah, Saudi Arabia. Since this is a baseline study being done in Majmaah, these risk factors were considered as optimal indicators for the risk of developing diabetes or hypertension..$^{22-24}$ The total response among the selected participants was $83.6 \%$ (794 out of 950 students included in the study). Table 1 shows the demographic characteristics of the participants. Most of the participants (89.2\%) were between 8 and 12 years of age. The study group was comprised of $64.4 \%$ male and $35.6 \%$ female students by the end of the research project. The total number of Saudi participants was $618(77.8 \%)$ while non-Saudi students $(22.3 \%)$ made up the balance.

Table 2 shows the distribution of waist to height ratios over the recommended $(>0.5)$ level in $16.8 \%$ of the children, which represents a risk for cardiovascular diseases and diabetes. Also, a positive family history ${ }^{25}$ of diabetes, hypertension, or both was found in $38.9 \%$ of the participants. About $43 \%$ of the participants habitually watched television or played video games for more than 3 hours a day, every day, which is regarded as a risky sedentary habit. Risky dietary habits included the consumption of carbonated drinks or sugary fruit juices daily (36.4\%). Also $17 \%$ of the children admitted to having food outside the home, particularly fast food from branded outlets, on more than 3 days of the week instead of consuming homemade food. ${ }^{26}$

Table 3 shows the BMI of school children differentiated by gender. Regardless of age and gender there were $11.6 \%$ (92) children who were having their BMI more than the normal range. Around $37 \%$ of the students were underweight $(\mathrm{BMI}<18.5)$. More boys $(6.0 \%$ and $1.8 \%)$ were overweight and obese respectively than girls $(3.4 \%$ and $0.4 \%)$. This was statistically significant at $95 \%$ confidence interval $(\mathrm{P}<0.001)$.

Table 1. Socio-demographic profile of the participants.

\begin{tabular}{lccc} 
Variables & Participants $(\mathrm{n}=794)$ & Number & $\%$ \\
Age in years & 6 & 13 & 1.6 \\
& 7 & 58 & 7.3 \\
& 8 & 117 & 14.7 \\
9 & 114 & 14.4 \\
& 10 & 202 & 25.4 \\
& 11 & 151 & 19.0 \\
& 12 & 124 & 15.6 \\
& 13 & 12 & 1.5 \\
& 14 & 2 & 0.3 \\
Gender & 15 & 1 & 0.1 \\
& Male & 511 & 64.4 \\
Ethnicity & Female & 283 & 35.6 \\
& Saudi & 618 & 77.8 \\
\hline
\end{tabular}


Table 4 shows the distribution of the mean values of anthropometric characteristics in the school children. The mean waist circumference in both male and female children increased continuously from 6 to 12 years comparatively except in females where there was a slight dip from 7 to 8 years. As seen, the mean values increase by $18.7 \mathrm{~cm}$ in males and $16.3 \mathrm{~cm}$ in females from age 6 to 12 years. Comparatively, the BMI reading was higher among boys than girls at each age group except after age 12 years when the girls BMI reading caught up with the boys. These differences were not statistically significant. No children were recorded in the age group 14 years in males and 13 years in females so the characteristics in those age groups are not seen.

Table 5 shows the percentile distribution of systolic blood pressure in both boys and girls. The systolic and diastolic blood pressure in the $50^{\text {th }}$ percentile is more frequent among boys than girls in the age group 6 to 7 years but after that age it is more common among girls than boys until the age of 12 years. As seen in the $50^{\text {th }}$ percentile, there is a gradual increase in the systolic blood pressure in boys while in girls there is a much larger increase by the age of 12 years. Between 7 and 8 years there is a dip in the systolic blood pressure in the $50^{\text {th }}$ percentile in girls in contrast to boys. In comparison with the standard reference by American Academy of Pediatrics, ${ }^{27}$ it is seen that the systolic and diastolic blood pressure across the percentiles are higher at all ages except in boys where it is almost at par in the initial years.

Table 2. Distribution of the risk factors associated with development of diabetes and hypertension among the school children.

\begin{tabular}{lcc} 
Risk factors & No. participants (n=794) & $\%$ \\
Waist-to-height ratio (WHR $>0.5)$ & 133 & $16.8 \%$ \\
Positive family history for diabetes and/or hypertension & 309 & $38.9 \%$ \\
\hline Mostly outside food intake & 139 & $17.5 \%$ \\
Sedentary activities for more than 3 hours per day & 341 & $43 \%$ \\
\hline Carbonated drinks/fruit juice & 289 & $36.4 \%$ \\
\hline
\end{tabular}

Table 3. Distribution of BMI and gender of the school children.

\begin{tabular}{lccc} 
BMI & Male & Gender, No (\%) & Total \\
\hline$<18.5$ & $161(20.3)$ & $134(16.9)$ & $295(37.2)$ \\
$18.5-24.99$ & $288(36.3)$ & $119(15.0)$ & $407(51.3)$ \\
\hline $25.0-29.99$ & $48(6.0)$ & $27(3.4)$ & $75(9.4)$ \\
$>30$ & $14(1.8)$ & $3(0.4)$ & $17(2.1)$ \\
\hline Total & $511(64.4)$ & $283(35.6)$ & $794(100.0)$ \\
\hline
\end{tabular}

$\mathrm{X}^{2}=21.99, \mathrm{df}=3, \mathrm{P}<0.001$.

Table 4. Distribution of mean anthropometric characteristics of school children.

\begin{tabular}{|c|c|c|c|c|c|c|c|c|}
\hline Age, years & No & Weight, kg & Height, cm & BMI, $\mathrm{kg} / \mathrm{m}^{2}$ & WC, cm & WHtR & Systolic BP, mmHg & Diastolic BP, mmHg \\
\hline \multicolumn{9}{|c|}{ Boys } \\
\hline 6 & 9 & $26.1 \pm 7.21$ & $119.2 \pm 10.06$ & $18.3 \pm 4.40$ & $56.4 \pm 4.05$ & $0.47 \pm 0.02$ & $97.4 \pm 9.10$ & $64.8 \pm 3.83$ \\
\hline 7 & 38 & $28.3 \pm 7.55$ & $122.6 \pm 6.78$ & $18.7 \pm 3.82$ & $59.9 \pm 9.05$ & $0.48 \pm 0.06$ & $99.4 \pm 10.7$ & $63.5 \pm 8.51$ \\
\hline 8 & 77 & $31.3 \pm 9.03$ & $127.2 \pm 9.24$ & $19.1 \pm 3.38$ & $61.1 \pm 9.45$ & $0.48 \pm 0.06$ & $100.5 \pm 12.91$ & $65.0 \pm 11.01$ \\
\hline 9 & 66 & $32.1 \pm 8.05$ & $130.9 \pm 7.14$ & $18.7 \pm 3.39$ & $63.9 \pm 9.22$ & $0.48 \pm 0.06$ & $102.2 \pm 13.00$ & $67.7 \pm 11.50$ \\
\hline 10 & 119 & $36.5 \pm 10.40$ & $133.4 \pm 8.35$ & $20.2 \pm 4.30$ & $67.9 \pm 11.78$ & $0.50 \pm 0.07$ & $104.8 \pm 12.6$ & $67.3 \pm 9.31$ \\
\hline 11 & 95 & $38.6 \pm 10.92$ & $136.7 \pm 7.52$ & $20.5 \pm 4.72$ & $72.0 \pm 12.80$ & $0.53 \pm 0.08$ & $107.8 \pm 10.3$ & $69.1 \pm 11.02$ \\
\hline 12 & 95 & $45.0 \pm 12.61$ & $141.6 \pm 9.52$ & $22.3 \pm 4.41$ & $75.1 \pm 12.0$ & $0.53 \pm 0.07$ & $112.1 \pm 13.01$ & $69.8 \pm 9.12$ \\
\hline 13 & 11 & $42.9 \pm 5.73$ & $140.0 \pm 7.25$ & $21.9 \pm 1.99$ & $69.5 \pm 7.60$ & $0.49 \pm 0.04$ & $112.9 \pm 9.38$ & $69.8 \pm 10.44$ \\
\hline \multicolumn{9}{|c|}{ Girls } \\
\hline 6 & 4 & $18.3 \pm 2.41$ & $109.3 \pm 3.69$ & $15.3 \pm 1.06$ & $49.0 \pm 0.82$ & $0.45 \pm 0.02$ & $92.0 \pm 4.08$ & $59.5 \pm 12.29$ \\
\hline 7 & 20 & $26.4 \pm 6.43$ & $120.1 \pm 6.25$ & $18.2 \pm 3.47$ & $57.5 \pm 6.57$ & $0.48 \pm 0.05$ & $100.5 \pm 0.79$ & $61.3 \pm 8.75$ \\
\hline 8 & 40 & $26.8 \pm 6.79$ & $122.5 \pm 6.50$ & $17.7 \pm 3.58$ & $56.2 \pm 7.31$ & $0.46 \pm 0.05$ & $103.6 \pm 13.39$ & $65.9 \pm 10.25$ \\
\hline 9 & 48 & $32.8 \pm 10.00$ & $129.0 \pm 10.63$ & $19.4 \pm 3.74$ & $59.8 \pm 7.74$ & $0.46 \pm 0.05$ & $107.6 \pm 14.79$ & $65.3 \pm 9.42$ \\
\hline 10 & 83 & $34.3 \pm 8.75$ & $133.6 \pm 7.33$ & $19.0 \pm 3.56$ & $59.5 \pm 7.02$ & $0.45 \pm 0.05$ & $107.4 \pm 13.66$ & $67.2 \pm 10.51$ \\
\hline 11 & 56 & $40.3 \pm 10.45$ & $138.2 \pm 16.49$ & $20.4 \pm 4.06$ & $626 \pm 7.88$ & $0.47 \pm 0.18$ & $109.9 \pm 12.40$ & $66.5 \pm 9.65$ \\
\hline 12 & 29 & $45.7 \pm 11.74$ & $142.7 \pm 6.67$ & $22.3 \pm 5.04$ & $65.3 \pm 9.97$ & $0.46 \pm 0.07$ & $115.2 \pm 13.90$ & $68.7 \pm 8.80$ \\
\hline 14 & 2 & $57.7 \pm 16.05$ & $159.5 \pm 2.12$ & $22.6 \pm 5.67$ & $72.5 \pm 16.26$ & $0.45 \pm 0.10$ & $123.5 \pm 20.51$ & $72.0 \pm 16.97$ \\
\hline
\end{tabular}

BMI, Body mass index; WC, Waist circumference; WHtR, Waist to height ratio; BP, Blood pressure. 


\section{Discussion}

The increasing prevalence of risk factors like excessive unhealthy food and drink consumption, a high BMI and sedentary lifestyles are ominous signs indicating that the precursors exist for an incoming pandemic of lifestyle diseases like diabetes and hypertension. Organizations like the United Nations, World Health Organization, and World Bank emphasize the need to focus on younger generations now to control the of non-communicable diseases in the future. ${ }^{28-30}$ Our study showed that $11.5 \%$ of the participants had a BMI above the normal range (18.5-24.9) which was a lower percentage than that reported in other similar studies done in Saudi Arabia (14-28\%). ${ }^{31-34}$ Other principal risk factors explored in this study showed that the waist-to-height ratio (WHtR) was more than the recommended limit in $16.8 \%$ of the children. Many studies have supported the use of WHtR inclusively in identifying at risk populations with prevalence ranging from $10-23 \% .35,36$

This study also revealed that $38.9 \%$ of the participants had a positive family history for diabetes and hypertension which independently is a strong predictor of its occurrence in later years. This finding is supported by studies such as an epidemiological profile of diabetes in Saudi Arabia by Tarik et al..$^{37}$ that points to an overwhelming genetic predisposition towards this disease while El-Hazmi et al. ${ }^{38}$ pointed out consanguinity as one of the primary reasons for it. Al Mouzan et $a l .{ }^{39}$ also found an association of consanguinity with diabetes in children though it was not statistically significant $(\mathrm{P}=0.92)$. Other risk factors such as sedentary activities like watching television or playing video games ( $>3$ hours per day) was prevalent among $43 \%$ of the participants. Studies such as those of Al Hazza ${ }^{40}$ and Al-Nuaim et al. ${ }^{41}$ have found that there is an association of physical inactivity with obesity and cardiovascular diseases later in life. In fact, the World Health Organization has declared physical inactivity to be one of the top five risk factors for premature mortality. ${ }^{42}$ Dietary choices like preference for food outside the home (fast food, restaurant meals, etc.) was found among $17.5 \%$ of the participants, coupled with a higher intake of carbonated drinks or sugary fruit juices (36.4\%) signaling a high risk for obesity and overweight among children in this study. Collison et al. ${ }^{19}$ showed that there was a significant increase in the consumption of sugar sweetened carbonated beverages among children 10 to 19 years as compared to non-sugar sweetened beverages. Basciano et $a l .{ }^{43}$ and James et al. ${ }^{44}$ have shown the association of carbonated beverages with obesity and overweight which are precursors of diabetes and hypertension. Likewise, El Mouzan et al. ${ }^{45}$ and Amin et al. ${ }^{46}$ showed a positive correlation between frequency of fast food intake among Saudi school children and increasing obesity and development of metabolic syndrome later in life. In our study, the measurements of systolic and diastolic blood pressure showed an increasing trend with age among both boys and girls at a higher level than the percentile reference it was compared with. ${ }^{18}$ We found that the children were at a higher risk of developing hypertension associated with the prevailing risk factors. Studies by Ataei et al. ${ }^{47}$ on children found elevated blood pressure among 287 students and Koura et al..$^{48}$ screened 370 young females in Dammam and found 13.5\% of them to be pre-hypertensive.

\section{Conclusions and recommendations}

This study highlights the prevalent risk factors for diabetes and hypertension at an early age which can potentially lead over time to the development of the disease. Primarily, it was observed that unhealthy diets, sedentary lifestyles and elevated BMIs are quite prevalent among the study population. In the present scenario, there are very few health warnings attractive enough to garner attention by the population against

Table 5. Distribution of systolic blood pressure in percentiles with age and gender of the school children.

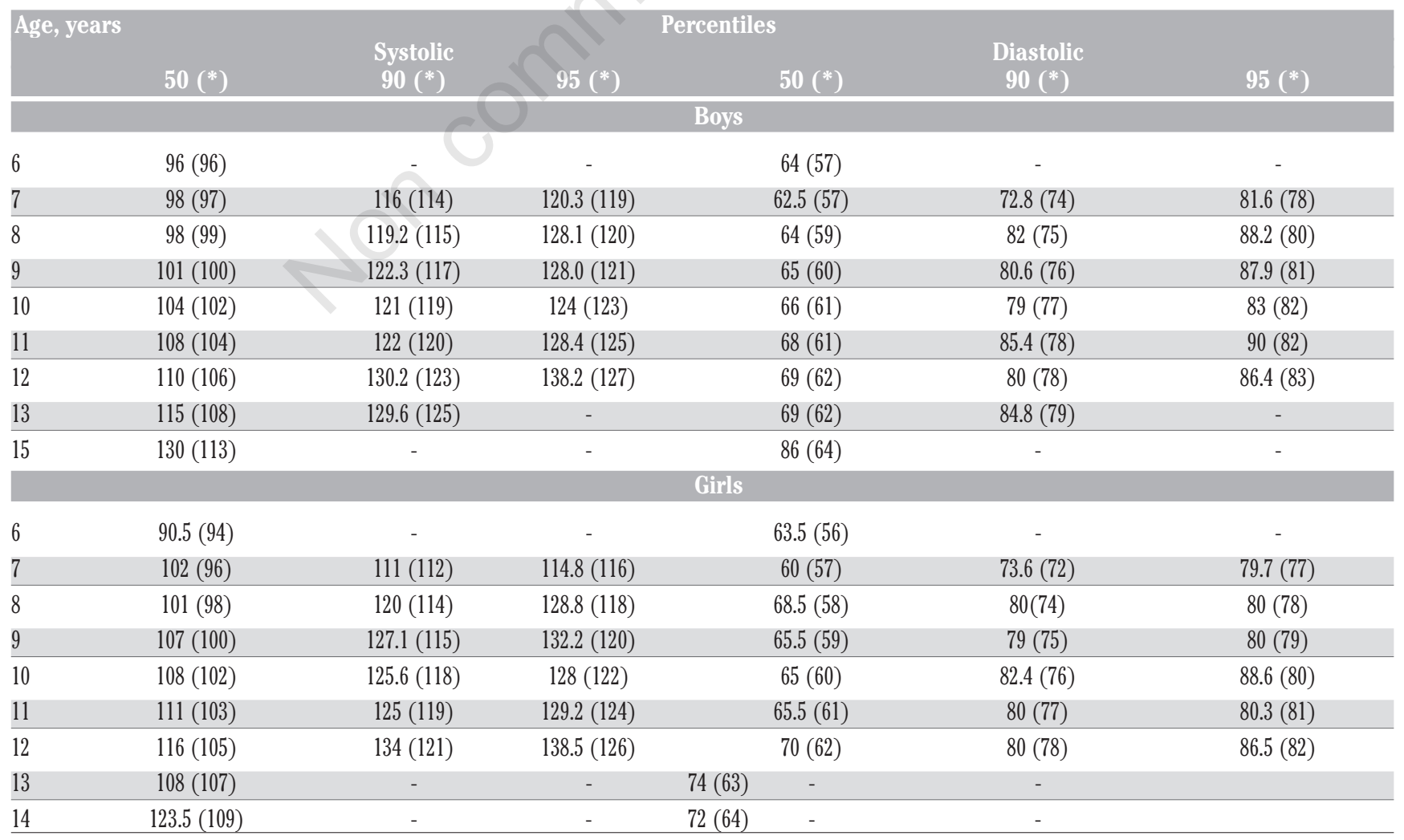

*Age and height percentile reference chart from American Academy of Pediatrics. ${ }^{27}$ 
these risk factors. Rather, there is a constant assault of advertisements, banners, posters, promotional campaigns for a glitzy lifestyle, and consumption of fast food, alcohol and tobacco as well as use of electronic gadgets that overwhelm the senses of many people. It is also seen that parents need more awareness about these risk factors and need to encourage their children to lead a healthy and active life. Even the website of the Ministry of Health of the Kingdom of Saudi Arabia provides very little information on the prevalence, awareness and consequences of risk factors for diabetes and hypertension among the population. ${ }^{49}$ Based on the findings of this study, we recommend a collaborative effort by the government agencies and non-government organizations to promote healthy behavior and lifestyle within schools and home environments. Regular promotional campaigns at key public places and social media should be the norm while appropriate legislative measures should be implemented nationally. Importantly, international cooperation among countries for disease prevention at an early stage of life should be a long-term goal.

\section{Limitations of the study}

The total duration of the study, though designed to be finished in one year, took longer than that as a result of logistic difficulties of getting ethics approval and permission from the Ministry of Education to collect data from school children in the school system. Out of the 950 students selected for this study, the total response was 794 (83.6\%) which could also be one of the limiting factors in the generalization of the result to the entire population.

Correspondence: Syed Meraj Ahmed, Department of Community Medicine, College of Medicine, Majmaah University, Majmaah 11952, Kingdom of Saudi Arabia.

Tel.: +96.6552194531.

E-mail: s.meraj@mu.edu.sa, merajahmed10@hotmail.com.

Key words: School children; risk factors; diabetes; hypertension; waist-hip ratio; Saudi Arabia.

Acknowledgements: We are grateful for the kind support and field study assistance by Dr. Usama Bin Ghaffar, Dr. Sajid Hussain, Dr. Sadig Mohamed, Dr. Khalid Tohami, Dr. Ali Faraz, Mr. Waqas Sami (statistical analysis), Dr. Nazia, Dr. Sawsan, Dr. Himmat and other female medical faculty members. We are also very grateful to the Department of Education, Majmaah, for allowing us to proceed with the study in their schools. We acknowledge the Deanship of Scientific Research, Majmaah University, Majmaah, Saudi Arabia for funding this study in full, without which it would not have been possible to perform the work.

Contributions: SMA, concept, design and the methodology of the study, development of the analysis, result and discussion part; first draft preparation and revision of the study for the authenticity of content and references; approved the final paper for publication; MAM, contribution to the design, methodology and results of the study; drafting the paper and critically revising it thoroughly for the authenticity of content and references; approved the final paper for publication purposes.

Conflict of interest: the authors declare no potential conflict of interest.

Received for publication: 20 February 2017.

Accepted for publication: 31 August 2017.

(C) Copyright S. Meraj Ahmed and M. Al Mansour, 2017

Licensee PAGEPress, Italy

Journal of Public Health Research 2017;6:829

doi:10.4081/jphr.2017.829

This work is licensed under a Creative Commons Attribution NonCommercial 4.0 License (CC BY-NC 4.0).

\section{References}

1. Riley M, Bluhm B. High blood pressure in children and adolescents. Am Fam Physician 2012;85:693-700.

2. Australian Government Department of Health and Ageing. Physical activity recommendations for 5-12 year olds. h t t p : / / w w w. he alth.gov. a u/internet/main /publishing.nsf/Content/health-pubhlth-strateg-physact-guidelines. Accessed June 30, 2016

3. Ness AR, Leary SD, Mattocks C, et al. Objectively measured physical activity and fat mass in a large cohort of children. PLoS Med 2007;4:e97.

4. Steele RM, Brage S, Corder K, et al. Physical activity, cardiorespiratory fitness, and the metabolic syndrome in youth. $\mathrm{J}$ Appl Physiol 2008;105:342-51.

5. Pontiroli AE. Type 2 diabetes mellitus is becoming the most common type of diabetes in school children. Acta Diabetol 2004;41:85-90.

6. Misra A, Khurana L, Vikram NK, et al. Metabolic syndrome in children: current issues and south Asian perspective. Nutrition 2007;23:895-910.

7. Bhardwaj S, Misra A, Khurana L, et al. Childhood obesity in Asian Indians: a burgeoning cause of insulin resistance, diabetes and sub-clinical inflammation. Asia Pac J Clin Nutr 2008; 17:172-5.

8. Fowler MJ. Microvascular and macrovascular complications of diabetes. Clin Diabetes 2008;26:77-82.

9. Egan BM, Zhao Y, Axon RN. US trends in prevalence, awareness, treatment, and control of hypertension, 1988-2008. JAMA 2010;303:2043-50.

10. Mohieldein AH, Alzohairy MA, Hasan M. Awareness of diabetes mellitus among Saudi non-diabetic population in AlQassim region, Saudi Arabia. J Diabetes Endocrinol 2011;2:14-9.

11. Aljoudi A, Taha A. Knowledge of diabetes risk factors and preventive measures among attendees of a primary care center in eastern Saudi Arabia. Ann Saudi Med 2009;29:15.

12. Hollar D, Messiah SE, Lopez-Mitnik G, et al. Effect of a twoyear obesity prevention intervention on percentile changes in body mass index and academic performance in low-income elementary school children. Am J Public Health 2010;100:64653.

13. Singhal N, Misra A, Shah P, Gulati S. Effects of controlled school-based multi-component model of nutrition and lifestyle interventions on behavior modification, anthropometry and metabolic risk profile of urban Asian Indian adolescents in North India. Eur J Clin Nutr 2010;64:364-73.

14. Al-Hazzaa HM, Abahussain NA, Al-Sobayel HI, et al. Physical activity, sedentary behaviors and dietary habits among Saudi adolescents relative to age, gender and region. Int J Behav Nutr Phys Act 2011;8:140.

15. Habeb AM, Al Magamsi MS, Halabi S, et al. High incidence of childhood type 1 diabetes in Al Madinah, North West Saudi Arabia (2004-2009). Pediatr Diabetes 2011;12:676-81.

16. Mahfouz AA, Shatoor AS, Khan MY, et al. Nutrition, physical activity, and gender risks for adolescent obesity in Southwestern Saudi Arabia. Saudi J Gastroenterol 2011;17: 318.

17. Al-Hazzaa HM. Prevalence and trends in obesity among school boys in Central Saudi Arabia between 1988 and 2005. Saudi Med J 2007;28:1569-74.

18. Farghaly NF, Ghazali BM, Al-Wabel HM, et al. Life style and nutrition and their impact on health of Saudi school students in Abha, Southwestern region of Saudi Arabia. Saudi Med J 
2007; 28:415-21.

19. Collison KS, Zaidi MZ, Subhani SN, et al. Sugar-sweetened carbonated beverage consumption correlates with BMI, waist circumference, and poor dietary choices in school children. BMC Public Health 2010;10:234.

20. World Health Organization. Growth reference 5-19 years. 2007. Available from: http://www.who.int/growthref /who2007_bmi_for_age_field/en/.

21. World Health Organization. Physical status: the use and interpretation of anthropometry: a report of a WHO expert committee. Geneva: WHO. 1995.

22. Kuba VM, Leone C, Damiani D. Is waist-to-height ratio a useful indicator of cardio-metabolic risk in 6-10-year-old children? BMC Pediatrics 2013;13:91

23. Maffeis C, Banzato C, Talamini G. Waist-to-height ratio, a useful index to identify high metabolic risk in overweight children. J Pediatr 2008;152:207-13.

24. Janssen, I, Katzmarzyk PT, Srinivasan SR, et al. Utility of childhood BMI in the prediction of adulthood disease: comparison of national and international references. Obesity 2005; 13:1106-15.

25. Valdez R, Greenlund KJ, Khoury MJ, Yoon PW. Is family history a useful tool for detecting children at risk for diabetes and cardiovascular diseases? A public health perspective. Pediatrics 2007;120:S78-86.

26. Powell LM, Nguyen BT. Fast-food and full-service restaurant consumption among children and adolescents: effect on energy, beverage, and nutrient intake. JAMA Pediatr 2013;167:1420.

27. National Institute of Health. The Fourth Report on the Diagnosis, Evaluation, and Treatment of High Blood Pressure in Children and Adolescents. Pediatrics. 2004;114. Available from: https://www.nhlbi.nih.gov/sites/www.nhlbi.nih. gov/files/hbp-ch.pdf

28. World Health Organization. New data highlight increases in hypertension, diabetes incidence. Available from: http://www.who.int/mediacentre/news/releases/2012/world_h ealth_statistics_20120516/en/ (Accessed on 25th October 2016)

29. World Health Organization. Hypertension and diabetes on the rise worldwide, says UN report. 2012. Available frm: http://www.un.org/apps/news/story.asp?newsid=42012\#.WD1 g--Z97IU

30. The World Bank. Diabetes prevalence (\% of population ages 20 to 79). Available from: http://data.worldbank.org/indicator/SH.STA.DIAB.ZS. Accessed on 25th October 2106

31. Alam AA. Obesity among female school children in Northwest Riyadh in relation to affluent lifestyle. Saudi Med J 2008;29.

32. El Hazmi M, Warsy AS. The prevalence of obesity and overweight in 1-18-year-old Saudi children. Ann Saudi Med 2002;22:303-7.

33. Al Nuaim AR, Bamgboye EA, Al Herbish A. The pattern of growth and obesity in Saudi Arabian male school children. Int J Obes Relat Metab Disord 1996;20:1000-5.

34. Amin TT, Al-Sultan AI, Ali A. Overweight and obesity and their relation to dietary habits and socio-demographic characteristics among male primary school children in Al-Hassa, Kingdom of Saudi Arabia. Eur J Nutr 2008;47:310-8.

35. Lam BC, Koh GC, Chen C, et al. Comparison of body mass index (BMI), body adiposity index (BAI), waist circumference (WC), waist-to-hip ratio (WHR) and waist-to-height ratio (WHtR) as predictors of cardiovascular disease risk factors in an adult population in Singapore. PLoS ONE 2015;10: $\mathrm{e} 0122985$.

36. El Mouzan MI, Al Herbish AS, Al Salloum AA, et al. Regional variation in prevalence of overweight and obesity in Saudi children and adolescents. Saudi J Gastroenterol 2012;18:129.

37. Elhadd TA, Al-Amoudi AA, Alzahrani AS. Epidemiology, clinical and complications profile of diabetes in Saudi Arabia: a review. Ann Saudi Med 2007;27:241.

38. El Hazmi MA, Al-Swailem AR, Warsey SA, et al. Consanguinity among Saudi Arabian populations.; J Med Genetics 1995;32:623

39. El Mouzan M, Al Salloum A, Al Herbish A, et al. Consanguinity and major genetic disorders in Saudi children: a community-based cross-sectional study. Ann Saudi Med 2008;28:169.

40. Al-Hazzaa H. The public health burden of physical inactivity in Saudi Arabia. J Fam Commun Med 2004;11:45-51.

41. Al-Nuaim AA, Al-Nakeeb Y, Lyons M, et al. The prevalence of physical activity and sedentary behaviours relative to obesity among adolescents from Al-Ahsa, Saudi Arabia: rural versus urban variations. J Nutr Metabol 2012;2012.

42. World Health Organization. Global recommendations on physical activity for health. Geneva: WHO; 2010.

43. Basciano H, Federico-Adeli K. Fructose, insulin resistance, and metabolic dyslipidemia. Nutr Metab (Lond) 2005;2:5-10.

44. James J, Kerr D. Prevention of childhood obesity by reducing soft drinks. Int J Obesity 2005;29:S54-7.

45. El Mouzan MI, Foster PJ, Al Herbish AS, et al. Prevalence of overweight and obesity in Saudi children and adolescents. Ann Saudi Med 2010;30:203.

46. Amin TT, Al-Sultan AI, Ali A. Overweight and obesity and their association with dietary habits, and sociodemographic characteristics among male primary school children in AlHassa, Kingdom of Saudi Arabia. Ind J Commun Med 2008;33:172.

47. Ataei N, Aghamohammadi A, Ziaee V, et al. Prevalence of hypertension in junior and senior high school children in Iran. 2008. Available from: https://tspace.library.utoronto.ca/handle/1807/58503. Accessed on 30th October 2016.

48. Koura MR, Al-Dabal BK, Rasheed P, et al. Pre-hypertension among young adult females in Dammam, Saudi Arabia. East Mediterr Health J. 2012;18:728-34.

49. Ministry of Health - Kingdom of Saudi Arabia. Diabetes: symptoms, complications, means of prevention and treatment. Available from: http://www.moh.gov.sa/en/HealthAwareness/ EducationalContent/Diseases/Endocrinology/Pages/001.aspx. Accessed on 7th July 2017. 